\title{
3 A Proposal for the Methodological Design of Col- laborative Language MOOCs
}

\begin{abstract}
The introduction of massive open online education has offered a new range of exciting possibilities for the development of language learning. By opening up access to language education for all who are digitally connected, it contributes to increase the speed and outreach of the dissemination of one of the key transversal competences. Additionally, it allows also for the acceleration of the language learning processes through the use of very large communities of practice. However, most of the MOOCs in offer today are not designed in such a way as to empower learners and favour collaborative learning experiences. In this chapter we explore how the massive open education movement has been evolving and discuss what the design elements favouring massive collaborative language learning experiences should be. We present a methodological proposal for collaborative language MOOCs based on the iMOOC model, developed by a team of the Open University of Portugal (Universidade Aberta - UAb.pt).
\end{abstract}

Keywords: language learning, massive collaborative learning, open education, MOOC, iMOOC

\subsection{The Rise of Digital Massive Open Education}

\subsubsection{The MOOC Phenomenon: between Large-Scale Content Distribution and Massive Collaborative Learning}

The pedagogical principles and practices followed by connectivist Massive Open Online Courses (MOOCs) and by those offered through Udacity, Coursera or edX are quite different (Daniel, 2012; Siemens, 2012; Watters, 2012). So different, in fact, that using the same name to designate them may be confusing (Hill, 2012). Downes proposed a useful distinction, calling the former cMOOCs and the latter xMOOCs (Watters, 2012), which has since been widely adopted.

The first MOOC bearing that designation was offered by George Siemens, Stephen Downes and Dave Cormier at the University of Manitoba, Canada, in 2008 (Downes, 2012; Daniel, 2012; Watters, 2012). The "Connectivism and Connective Knowledge" course (CCK08) set itself in the larger context of Open Education and Open Educational Resources (OERs), following a practice of sharing with the world the results of regular academic work. 
CCK08 was designed according to the connectivist principles of learning (Downes, 2012; Siemens, 2012; Cormier, 2010), based on a participatory pedagogy and on networked learning. There was not a fixed body of content to be learned, 'professors' teaching 'students' or a single location where the course took place. Content resulted from the production of artefacts by participants, following their interaction with and their reflection upon a given set of resources (and other resources shared by them or by others), as well as the dialogue among participants around these artefacts; the organizers acted more as facilitators and providers of some necessary structure, with the 'teaching' role being assigned to the learning community itself; and, while there was a course site, with the relevant information (weekly topics, list of suggested resources, synchronous session schedule, etc.) and Moodle forums where people could interact, the conversation was distributed by the participants' own spaces (mostly individual blogs) and several social spaces (Twitter, Facebook, Second Life, etc.).

Contrary to common belief, MOOCs were not the creation of a number of high profile professors (Sebastian Thrun, Peter Norvig, Daphne Koller or Andrew Ng) from Stanford University, in 2011. Neither were these personalities "online learning pioneers”, as some uniformed writers state. In fact, their approach to MOOCs was quite distant from the original concept, following closely the model of formal higher education (lectures, assignments, assessment) and adopting a relatively limited understanding of what "open" means in this context. However, they were undoubtedly responsible for setting in motion what would become the educational phenomenon of 2012 (Daniel, 2012). In fact, because of their reputation and the media coverage they received, the discussion about online learning was brought to centre stage. They helped popularize a new idea of how to offer "education" at a massive scale, which can be seen as a positive contribution.

Thrun, the major figure in this movement, has since then become disenchanted with MOOCs, announcing that Udacity would abandon them and focus on corporate training, because he felt "[w]e were on the front pages of newspapers and magazines, and at the same time, I was realizing, we don't educate people as others wished, or as I wished. We have a lousy product" (Chafkin, 2013). Coursera, on the other hand, is still going strong. Despite the recent announcement by co-founder Ng that he would be stepping down from an active role ( $\mathrm{Ng}, 2014)$, the company claimed impressive numbers in November, 2013, in a post titled "A Triple Milestone: 107 Partners, 532 Courses, 5.2 Million Students and Counting!” (Coursera blog, 2013).

The downside to this success, however, is that they disseminated a model for MOOCs that dilutes much of the transformative and innovative potential that the initial concept carried, by ignoring not only the previous work done in the field of Open Education in general, and of MOOCs in particular, but also the bulk of more than 20 years of research and practice in online learning. Consequently, most people in academia as well as the public in general see MOOCs as a synonym for "teaching classes online to a high number of students", without a sound understanding of how the notions of "open" and "massive" were the real change operators in the 
initial concept, or of the history and practice of distance and online education. Furthermore, as universities became interested in MOOCs, the " $\mathrm{x}$ " model seemed right. After all, given its characteristics, universities can claim to be innovating while, at the same time, not changing much of their culture and pedagogical practices. Recent developments, such as small private online courses (SPOCs), represent at best this misconception.

MOOCs are a developing field, with a great deal of experimentation going on and many relevant questions still to be answered (Watters, 2012). Completion rates are low in all of them (Jordan, 2013; Daniel, 2012; Hill, 2012; Holton, 2012) and problems related with participants' satisfaction, learning support, technological environment and the quality of the learning experience are yet to be fully addressed (Daniel, 2012; Holton, 2012; Kop, Fournier \& Mak, 2011; Siemens, 2010).

From our perspective, however, MOOCs should be seen as non-formal online learning experiences and, therefore, clearly differentiated from the typical formal educational offerings.

\subsubsection{The iMOOC Approach: a Possible Synthesis?}

The introduction of MOOCs in higher education institutions poses an important challenge: how to combine typical non-formal learning experiences with a formal education setting? One solution is to use a model which basically replicates an instructional approach. A more innovative perspective is to find a synthesis that articulates the potential of the networked learning approach with the structure of higher education pedagogy. In our view, this can best be exemplified in the iMOOC model which we developed at Universidade Aberta (UAb.pt).

This was the first known institutional model specifically designed for open courses, in particular MOOCs. It was conceived to be compatible with the university's learning culture by building upon the four main pillars of its Pedagogical Model: learner-centredness, flexibility, interaction and digital inclusion (Pereira, Mendes, Morgado, Amante, \& Bidarra, 2008). Our goal was to combine autonomous and self-directed learning with a strong social dimension and the interaction that make learning experiences richer and more rewarding. We also wanted to articulate the flexibility that distance online learners need, especially adults with demanding professional and personal lives, with the pacing necessary to help them get things done. We sought to make learning available to as many people as possible, but also to bring these people into the digital online environment, where a crucial part of modern life happens, thus helping curb the digital divide.

The model draws mostly on cMOOCs but incorporates elements from other existing approaches, adding some relevant aspects that derive from our experience with online learning and its integration in the larger context of UAb.pt's Pedagogical Model, as well as the work that has been done regarding Open Educational Resources 
(OERs) and Open Educational Practices (OEPs). The most important principles are those described in the next paragraphs.

Courses are open to everyone who wants to participate. Registration is required for publishing in the institutional spaces but all content is open access, i.e. anyone can read it. The first week of the course is meant for participants to get acquainted with the spaces, tools and services, as well as with the processes of work and communication that will be used in the course. This "familiarization" process, a sort of "boot camp” week, already present in UAb.pt's Pedagogical Model as a stand-alone module that all students have to take when they start their learning at UAb.pt, has proved to be an essential component in student success and satisfaction regarding their online learning experience.

Resources provided as a starting point for the realization of the activities are licensed as OERs or freely available on the Internet. Content produced by participants is licensed according to the individual preference of the authors.

The iMOOC is learner-centred and learning is based on the realization of activities. It should be evidenced through the creation of artefacts (texts, videos, presentations, slidecasts, mind maps, mash-ups, etc.) that demonstrate the learner's knowledge and competencies regarding the material studied. These artefacts are published online. The learning process combines autonomous self-study and reflection with interaction with other participants in an open social context. Participants are expected to take an active role and be responsible for their own learning, but also to actively engage in helping build a supporting learning community.

There should be a central place for the course - this could be a website (webpage, wiki, blog, etc.), or an LMS (Moodle, for example), etc. where all relevant information is provided (content, resources, schedule, instructions, etc.) - but most of the work and interaction should benefit from a networked learning perspective, whereby students use their own Personal Learning Environments (PLE) to manage their learning, publish their artefacts and engage in conversation with other participants. Where it seems more adequate, an institutionally supported PLE may be used, i.e. a platform that emulates the experience of using a PLE by offering several Web 2.0 tools and a social networked environment but in an integrated platform supported by the institution.

Individual support or tutoring is impossible in a massive course. While there should be suggested activities and guidance from the course organizers, these can be carried out only at a more general level. Learning support has to rest in the learning community, through collaboration, dialogue, peer feedback and active engagement from participants in the learning process. A small team of collaborators can be used to support the implementation of the course - gathering relevant information to be used to monitor and perfect the ongoing process, serving as community facilitators, monitoring social or information networks for course related content, elaborating weekly summaries, etc. This may prove very helpful for the professor or professors leading the course to plan their intervention where necessary. 
Formative assessment can take the form of self-correction tests and also of peer feedback regarding the artefacts produced in the learning activities. Other strategies can be used to provide feedback of participants' activity - different recommender systems or badges for the completion of tasks or for relevant contributions to the community are two possible examples. Graded assessments are included for participants who want to receive a certificate of completion of the course. In this case, at least two of the artefacts produced as evidence of learning by participants will be assessed and graded through a peer-review system - those who wish to participate in the peerreview assessment will grade the artefacts produced by three other participants and have their artefact graded by three other participants. The final grade will be the average obtained in the three grades given. E-portfolios can also be used for grading purposes wherever they are considered adequate. The assessment follows the same peer-review procedure. Every assessment will be based on a detailed rubric provided by the professor or professors leading the course.

MOOCs in the pedagogical model described, following the current terminology, are therefore labelled iMOOCs, given their focus on individual responsibility, interaction, interpersonal relationships, innovation and inclusion.

\subsection{Massive Language Education}

\subsubsection{The Importance of Competence-Based Learning for Language Education in a $21^{\text {st }}$ Century Setting}

The rise of open education is also linked with the promotion of competency-based approaches in education. In fact, this new approach holds significant potential as learning opportunities can be developed outside classrooms, without following rigid pre-determined curricula. This has widened participation in the education system by many socially challenged groups, such as mature learners, and basically has contributed to open up education not only to all citizens, but also to allow for different social, geographical or time circumstances.

By competence, we mean the proven ability to use knowledge, skills and personal, social and/or methodological abilities in work or study situations and in professional and personal development (European Communities, 2008). The implementation of competence-based learning (CbL) has, therefore, led to a shift in focus from a teacher-centred perspective of the educational process to a new student-centred one, stressing the importance of what students need to know and be able to do in varied and complex situations. $\mathrm{CbL}$ is therefore focused on outcomes (competencies) that are linked to workforce needs, as well as social needs. The outcomes of a competencebased approach are by definition complex and subject to change. 
In view of this, $\mathrm{CbL}$ methodologies require more sophisticated assessment systems, involving portfolios, experiential learning assessment in field experience, demonstration in diversified contexts, role play, use of standardized learning models, etc. Large skill sets are broken down into competencies, which may have sequential levels of mastery. Competencies reinforce one another from basic to advanced, as the learning progresses.

Competencies within different contexts may require different bundles of skills, knowledge and attitudes. The challenge is to determine which competencies can be bundled together to provide the optimal grouping for performing tasks required. Another challenge is to design learning experiences that support students as they practice using and applying these competencies in different contexts.

$\mathrm{CbL}$ should be used in conjunction with the creation of meaningful opportunities for learners and professional practice in learning environments where they can develop integrated, performance-oriented capabilities for handling the core problems in real contexts.

Figure 3.1 below attempts to capture some of the core elements that differentiate traditional learning and competence-based, $21^{\text {st }}$ century learning.

\section{Competence-based, 21st century learning}

- Learner-centred

- Personalized

- Flexible

- Social/collaborative nature

- Challenging

- "Messy"

- Contextual

- $\quad$ Real life like, authentic

- "Gamified"

- Questioning/creating knowledge

- $\quad$ Experimenting; mistakes as learning opportunities

- $\quad$ Problem solving

- Artefacts/complex objects/eportfolios

\section{Traditional learning}

- Content-centred

- Uniform

- Rigid

- Highly structured

- Centralized

- Competitive nature

- Academic, curricular

- Memorizing/reproducing information

- Mistakes as failure; fear of experimenting outside the given parameters

Tests / Exams

Figure 3.1: Elements that differentiate traditional learning and competence-based learning

When we look at the language-learning field today, there is a great diversity of conceptual and pedagogical approaches that translate into very different methodologies used. From traditional drill-and-practice, grammar-based learning, to the notionalfunctional structuring of a syllabus, from more cognitive stances to sociocultural perspectives, focused on communicative skills and real interactions in context, they all coexist in current practices, very often mashed-up by teachers who alternate the different approaches in their work with the students. In a recent study, Myles (2013) analysed the major theoretical families in Second Language Acquisition (SLA) research 
and found "a plethora of different and seemingly conflicting claims" (2013: 46), concluding that, because of the complexity of language and language learning, it was unfeasible to agree upon a single SLA theory. The fact is that there has never been an authoritative study that could prove, beyond assumptions and based on hard data, the superiority of a method or approach over the others.

However, if we move past language learning in abstract and frame it within the context of 21st century learning, then we may start to identify which of these approaches are more fit and have greater potential. In a globalized, technologically connected world, "the focus in language education (...) is no longer on grammar, memorization and learning from rote, but rather using language and cultural knowledge as a means to communicate and connect to others around the globe." (Sarah E. Eaton, 2013).

This entails a learner and community/networked centred approach that values learner autonomy and collaborative learning, on the one hand (Jacobs \& Farrell, 2001, see Eaton, 2013; MLTASA, n.d.) and, on the other hand, a focus on knowledge creation and application, whereby learners demonstrate their understanding, reflection and competences through different types of artefacts that they share publicly and which foster dialogue, contrasting perspectives and critical thinking (Eaton, 2013; MLTASA, n.d.).

People are increasingly exposed to a greater cultural and linguistic diversity due to the abundance of information present in the media and made available by technological advances. At the same time, the world has become more interdependent and connected, and the opportunities and desire for communicating and collaborating with people in other countries, or for spending some time there, be it for educational, working, voluntary action or leisurely purposes have never been so high. Competence-based, $21^{\text {st }}$ century language learning provides not only a better understanding of the world and a deeper cultural awareness, but also empowers learners with much needed communication and interaction capabilities.

\subsubsection{Some Challenges in Designing Language Learning MOOCs}

Whereas a decade or so ago learning languages online could be a difficult challenge to overcome, technological development and the abundance of resources, either open licensed or freely available online, have minimized such difficulties. Online learning has, from its inception, adopted mostly a social constructivist, collaborative approach. From the first experiences with discussion forums to concepts like the " 5 Stage Model” (Salmon, 2000) or the "Community of Inquiry” (Garrison \& Anderson, 2003), online learning approaches have always valued autonomy, learner-centredness, critical thinking, dialogue and interaction, and learning in a social context. More recent learning theories in this field, like Connectivism (Siemens, 2005; Downes, 2005), have 
looked at how people learn in a highly digital, connected environment, and expanded these principles to community and networked learning settings.

To that extent, one could say that pedagogical approaches to online learning are very competence-based and incorporate many of the key aspects generally included in $21^{\text {st }}$ century learning skills. The real challenges in designing MOOCs come from the "massive" nature of these courses, and language learning poses some specific challenges of its own: the need for small group oral interactions or the tradition of learning by levels are two of the elements that present a higher degree of difficulty.

The massive number of participants forces the design of strategies that can promote small group interaction for oral practice-Skype, Google Hangouts, or similar services are effective, but how to organize the formation of groups in a universe that can reach tens (or even hundreds) of thousands of participants?

Automatically formed groups are a possibility, albeit a technically demanding one. However, given the different patterns in access frequency, pace in the performance of tasks and dropout rate known in MOOCs, many participants may find themselves in empty or greatly reduced groups, and without an easy path to move on to another functional group. Self-organized groups may be a good idea, but how can one support the creation of these groups by participants? A less rich, but still viable alternative, could be tasks built around audio production and exchanges, either in the form of a podcast, "discussion", “comments" or "debate”, to give some examples.

Furthermore, the presumable heterogeneity of the learning community when it comes to language knowledge and skills will require a choice of whether to organize the course by common reference levels (Council of Europe, 2001); to offer the course only for a specific level; or to allow for a mixed, multi-level environment, which will imply the design of a diversity of paths and tasks that can foster learning at different levels of difficulty and complexity.

Ultimately, organizing a language learning MOOC will require some complex decisions to be made, including the willingness to take some risks and experiment with strategies that have not been tested yet and may or may not work as intended. There are no recipes or safe practices in an emerging field where much of the knowledge is being drawn from experimenting, analysing, adjusting and iterating.

\subsubsection{Designing Collaborative Language MOOCs Based on the iMOOC Approach}

In the past, distance education found some solutions that proved to be effective in dealing with very large numbers of students, but they are not adequate for the kind of learning approach we have described earlier. When we look at the current MOOC landscape, the more dominant XMOOC model may be effective for some more conventional language learning approaches, but it does not seem fit for language learning in a $21^{\text {st }}$ century context as we have characterized it before. 
On the other hand, cMOOCs have a great potential in terms of the core principles of this approach. In the case of language MOOCs, however, participants at a lower level in terms of their current language skills may face an additional hurdle in being able to orientate themselves in a very distributed, networked environment.

The heterogeneity of learners and of their competences, wider than what can generally be observed in other fields or contexts, calls for a more scaffolded approach, where participants have a better, more structured support for their learning.

The iMOOC pedagogical approach can be most appropriate for designing collaborative language MOOCs. In fact, by focusing on the empowerment of the learners not just in an autonomous way but as part of a learning community, the iMOOC model meets the basic requirements of language learning massive courses. Our methodological proposal is, therefore, based on the iMOOC model, which will be explained in the following sections.

\subsubsection{Technological Environment}

A Learning Management System (LMS) should be used to centralize the main information regarding contents, resources, suggested activities, schedule, learning guide, relevant course announcements, etc. It should also harbour the discussion forums, one of the places where participants can interact and debate relevant aspects of course content and activity. Examples of this type of system include Moodle (free, open source) and Blackboard (proprietary, but with free hosting at https://www. coursesites.com/), among others. Many institutions will already have some type of LMS that can be used for this.

Instead of relying on the participants' PLEs for the social, collaborative context, we suggest the use of Elgg (http://elgg.org/), a free, open source social networking platform that has great potential to be used as an institutionally supported PLE. It has a variety of web 2.0 tools and social networking functionalities, such as rich profiles, microblogging, blogs, social bookmarking, photo and video publishing, recommender system, wiki-like pages, etc., with the advantage of providing these tools and services in an integrated, user-friendly platform supported by the institution. There should be a single sign-on system implemented between Elgg and the institutional LMS, and the two platforms should be further integrated by allowing students to access content in the LMS from within Elgg.

\subsubsection{Course Duration}

The course should run for about six or seven weeks, which seems an adequate length according to some empirical data (Weller, 2013). The first week should be dedicated to the familiarization process - a sort of "boot camp" to get participants acquainted and familiar with the environment, technologies and processes to be used throughout the course. This is a key phase in the process and may contribute significantly to a 
better retention rate, not only because it gives participants enough time to become sufficiently proficient to be able to work and communicate online before starting to engage with course contents, but also because it fosters the development of the learning community that is paramount in this approach. The remaining weeks should be organized around topics, with a short (5 to 10 minute) introductory video for each topic.

\subsubsection{Learning Process}

Ideally, in the week prior to the course (or during the first week, if that's not possible) participants should take a placement test with automatic results to check their language level. This will serve as a guide for them even if the course is not clearly organized by levels.

Learning should be based on the realization of tasks. In this model, participants are expected to study independently, exploring the resources, searching and exploring other relevant material on their own, doing the activities and reflecting on their learning experience, and producing artefacts that demonstrate their understanding of the topics and their competences in applying that knowledge. They are also expected to engage in the interaction with other participants and to take an active role in the dialogue around the topics being dealt with, contributing in relevant ways to the creation of knowledge in a shared, social context. They are responsible for their own learning and for helping shape a dynamic, supporting learning community as well.

\subsubsection{Teacher's Role}

Teacher presence and workload have to be carefully considered. Learning support cannot be assured through direct and ongoing teacher intervention. It has to rest in the documentation and resources provided, in strategically scheduled communications from the teacher and in an active and engaged learning community. Teacher/ teaching presence is created through the learning guide, the detailed instructions for the tasks, the introductory videos for each topic and a weekly feedback message, based on the information prepared by the support team. One or two synchronous sessions (Google Hangout, web conference, etc.) during the course (third and fifth week, for example), preferably with one or several relevant guests, should be used to increase teacher/teaching presence, strengthen the social ties in the learning community and serve as "magnets" for retention.

\subsubsection{Support Team}

A small team of volunteers should be recruited in order to collaborate with the teacher leading the course. This support team will gather information that may be relevant to monitor course progress and substantiate the teacher's weekly feedback, act as 
"community facilitators" and help out in setting and deploying the synchronous sessions, polls, peer assessment and other tasks considered necessary.

\subsubsection{Resources}

Resources must be provided - mostly OERs available that meet the course needs, or resources produced by the institution and published with an open license, coupled with other material that is freely available online - as a starting point to support the activities designed, but participants should also contribute with other resources that they search and share. The artefacts produced and published by participants throughout the learning process also become part of the course materials, i.e. they are available for other participants to learn from them. Participants should be encouraged to publish these resources as OERs, but ultimately it is up to them to make that decision.

\subsubsection{Activities/Tasks}

A variety of suggested tasks should be made available, supporting and scaffolding participants' exploration, reflection, production and dialogue. As far as possible, these tasks should be authentic, i.e. emulating or mobilizing real life settings, flexible and open ended, which means participants should ideally have a fair amount of choice concerning the process of performing the task and its output - the artefact they will produce. Tasks should also be designed in such a way that they can be performed at different levels of difficulty or complexity, to account for the expected broad spectrum in participants' language skills. If it seems more appropriate, tasks can be organized by level, using the Common European Framework of Reference for Languages (Council of Europe, 2001). In this case, instead of one single task, there can be different versions of the same task, one for each level covered.

In any case, smaller self-generated "by level" communities can be formed around these tasks, in which people collaborate more systematically for certain purposes, while maintaining connections and interacting in the wider community/network.

\subsubsection{Bank of Challenges}

A "bank of challenges", much in the spirit of DS106" "bank of assignments" can be used to complement the regular tasks, allowing participants to do more and explore other types of activities if they wish to do so. The fulfilment of these challenges may be rewarded with badges, thus allowing for them to be included in the participants' e-portfolio and subsequently used for certification or formal accreditation purposes.

3 Digital Storytelling-DS106-is an open, online course offered at the University of Mary Washington - http://ds106.us/ 
Following the same principle as the tasks designed, these could be offered in a single version or organized using the same level system, although many of them could be transversal to all levels, and differentiated in terms of the output through badges that specify different levels of accomplishment. This greatly improves flexibility regarding participants' opportunities to experiment with different types of tasks and different levels of complexity at their choice in a playful manner.

Suggestions for challenges can be contributed by participants and those reaching a defined point of agreement by the community - either using polls or other voting systems - should be included in the bank.

\subsubsection{Oral Practice}

A good part of oral practice can be covered in the tasks suggested or in the bank of challenges through the use of recorded audio, shared either as a simple audio file, as a video of the participant speaking, as a narrated video or presentation, or as a regular podcast that participants need to maintain throughout the course, using a free podcast hosting service, and in which they have to publish a defined number of "instalments" (4, for example). Applications like VoiceThread (https://voicethread. $\mathrm{com} /$ ), for instance, can also be used to foster oral communication and practice. The harder part in a MOOC, as previously stated, is to provide opportunities for real time (synchronous) oral interaction in a small group of, let's say, 6 to 10 people, who can then use Skype, Google Hangouts or similar applications to have regular conversations, either at their own will or included in the tasks suggested.

Here a choice needs to be made on how to organize these groups, but there needs to be a 'plan B' in place in case the adopted strategy fails completely. Groups present some difficult challenges, both technically and organizationally, at a massive scale, and it is important that course organizers are prepared to overcome problems if they arise.

There are at least 3 possible options, and certainly course organizers may think of others:

1. Auto-generated groups - when participants access the LMS, they are automatically assigned to a group (this may pose the problems mentioned before).

2. There are no pre-arranged groupings and participants enrol in a group up to a certain number, after which the group accepts no more members. This seems more flexible, since people can move to another group that still has vacancies if their group becomes non-functional. Groups can be identified by level, so, again, it is a more flexible solution, since people can choose a level they feel comfortable to interact orally.

3. Self-organized groups - this seems a good solution, as participants can cluster together in small groups that they themselves organize, and is more "organic", i.e. more similar to the way people self-organize in networks and communities. 
The downside is that many participants, for a variety of reasons, might be unable to join a group or attract other people to their group.

\subsubsection{Feedback}

Formative assessment with self-correction should be made available (through tests, quizzes, etc.), but participants must also be encouraged and are expected to discuss and give feedback to one another throughout the learning activities. A regular, more general feedback on the work done each week should be provided by the teacher, based on the information prepared by the support team.

\subsubsection{Certificate of Completion}

In our proposal, participants who wish to receive a certificate of completion will have to present an e-portfolio containing a relevant sample of their work in the course, which will be assessed by peers. This e-portfolio should include at least two of the artefacts produced, the badges collected (from completing challenges, for example) and other relevant contributions (other publications not included in the tasks). A qualitative scale can be used for grading: A) Very good B) Good C) Fair D) Fail. Those who wish to participate in the peer-assessment process will grade the e-portfolios produced by 3 other participants. Each e-portfolio will be graded by three different participants. The final grade will be the average obtained in the 3 grades received. This assessment will be based on a detailed rubric provided by the professor or professors leading the course.

\subsubsection{Formal Accreditation}

We believe participants should be able to obtain formal credits for their work in the course, for a fee. This will provide a seamless and articulated path from non-formal learning experiences to formal education. Those credits can be awarded following an evaluation by a professor or tutor of the e-portfolio presented by the participants (50\%), combined with a final, face to face exam (50\%) that must test all 4 skills.

\subsection{Final Remarks}

MOOCs offer a new range of exciting possibilities for the development of language education, since they allow for the creation of very large communities of practice, this feature being a critical element in a successful language learning experience. However, most current pedagogical approaches used in MOOCs do not empower learners and/or favour collaborative learning experiences. In this chapter we demonstrate how a synthesis between a networked learning or connectivist approach and 
a more structured one is possible and can lead to a much more effective language teaching and learning methodology. We have highlighted the main features of the iMOOC Pedagogical Model developed at UAb.pt, which we believe represents at best that synergy, and explored how it can be used to develop successful collaborative language MOOCs.

\section{Bibliography and Webliography}

Chafkin, M. (2013, November 14). Udacity's Sebastian Thrun, Godfather Of Free Online Education, Changes Course. Fast Company. Retrieved from http://www.fastcompany.com/3021473/ udacity-sebastian-thrun-uphill-climb.

Cormier, D. [dave cormier]. (2010, December 8). What is a MOOC? [Video file]. Retrieved from http:// www.youtube.com/watch?v=eW3gMGqcZQc.

Cormier, D. (2008, October 2). The CCK08 MOOC - Connectivism course, 1/4 way [Blog post]. Retrieved from http://davecormier.com/edblog/2008/10/02/the-cck08-mooc-connectivismcourse-14-way/.

Council of Europe (2001). Common European Framework of Reference for Languages. Cambridge: Cambridge University Press.

Coursera Blog (2013, October 23). A Triple Milestone: 107 Partners, 532 Courses, 5.2 Million Students and Counting! [Blog post]. Retrieved from http://blog.coursera.org/post/64907189712/a-triplemilestone-107-partners-532-courses-5-2

Daniel, J. (2012). Making Sense of MOOCs: Musings in a Maze of Myth, Paradox and Possibility. Journal Of Interactive Media In Education, 3(0). http://www-jime.open.ac.uk/jime/article/ view/2012-18.

Downes, S. (2012, January 6). Creating the Connectivist Course. [Blog post]. Retrieved from http:// halfanhour.blogspot.pt/2012/01/creating-connectivist-course.html.

Downes, S. (2005, December 12). An Introduction to Connective Knowledge. Stephen's Web. Retrieved from http://www.downes.ca/cgi-bin/page.cgi?post=33034.

Eaton, S. E. (2010). Global Trends in Language Learning in the Twenty-first Century. Calgary: Onate Press. Retrieved from http://files.eric.ed.gov/fulltext/ED510276.pdf.

Garrison, R., \& Anderson, T. (2003). E-Learning in the 21st Century: A Framework for Research and Practice. London \& New York: RoutledgeFalmer.

Hill, P. (2012, July 24). Four Barriers that MOOCs must overcome to build a sustainable model [Blog post]. Retrieved from http://mfeldstein.com/four-barriers-that-moocs-must-overcome-tobecome-sustainable-model.

Holton, D. (2012, May 4). What's the "problem" with MOOCs? [Blog post]. Retrieved from http:// edtechdev.wordpress.com/2012/05/04/whats-the-problem-with-moocs.

Jordan, K. (2013, February 13). Synthesising MOOC completion rates [Blog post]. Retrieved from http://moocmoocher.wordpress.com/2013/02/13/synthesising-mooc-completion-rates.

Kop, R., Fournier, H., \& Mak, J. (2011). A pedagogy of abundance or a pedagogy to support human beings? Participant support on massive open online courses. The International Review Of Research In Open And Distance Learning, 12(7), 74-93. Retrieved from http://www.irrodl.org/ index.php/irrodl/article/view/1041/2025.

Modern Language Teachers Association of South Australia [MLTASA] (n.d.). A rationale for language learning in the 21st century. Retrieved from http://mltasa.asn.au/a-rationale-for-languagelearning-in-the-21st-century/.

Myles, F. (2013). Theoretical Approaches. In J. Herschensohn \& M. Young-Scholten, Martha (Eds.). The Cambridge Handbook of Second Language Acquisition (pp. 46-70). Cambridge: CUP. 
$\mathrm{Ng}$, A. (2014, May 16). A personal message from Co-founder Andrew Ng [Blog post]. Retrieved from http://blog.coursera.org/post/85921942887/a-personal-message-from-co-founder-andrew-ng.

Pereira, A., Mendes, A. Q., Morgado, L., Amante, L., \& Bidarra, J. (2008). Universidade Aberta's pedagogical model for distance education: a university for the future. Lisbon: Universidade Aberta. Available at https://repositorioaberto.uab.pt/handle/10400.2/2388.

Salmon, G. (2000). E-Moderating: The Key to Teaching and Learning Online. London: Kogan Page.

Siemens, G. (2012, June 3). What is the theory that underpins our moocs? [Blog post]. Retrieved from http://www.elearnspace.org/blog/2012/06/03/what-is-the-theory-that-underpins-our-moocs/.

Siemens, G. (2010. December 19). What's wrong with (M)00Cs? [Blog post]. Retrieved from http:// www.elearnspace.org/blog/2010/12/19/whats-wrong-with-moocs.

Siemens, G. (2005). Connectivism: A Learning Theory for the Digital Age. International Journal of Instructional Technology and Distance Learning, 2 (1). Retrieved from http://www.itdl.org/ Journal/Jan_05/article01.htm.

Teixeira, A., \& Mota, J. (2013). Innovation and Openness through MOOCs: Universidade Aberta's Pedagogic Model for Non-formal Online Courses. Proceedings of the EDEN 2013 Annual Conference (pp. 479-488).

Teixeira, A., \& Mota, J. (n.d.). iMOOC Model. Retrieved from http://imooc.uab.pt/model_en.

Watters, A. (2012, December 3). Top Ed-Tech Trends of 2012: MOOCs. Hack Education. Retrieved from http://hackeducation.com/2012/12/03/top-ed-tech-trends-of-2012-moocs.

Weller, M. (2013, December 12). Completion data for MO0Cs [Blog post]. Retrieved from http:// nogoodreason.typepad.co.uk/no_good_reason/2013/12/completion-data-for-moocs.html. 